\title{
Evaluating the Effectiveness of the Rural Minimum Living Standard Guarantee (Dibao) Program in China
}

DOI:

10.1016/j.chieco.2018.07.010

Document Version

Accepted author manuscript

Link to publication record in Manchester Research Explorer

\section{Citation for published version (APA):}

Kakwani, N., Li, S., Wang, X., \& Zhu, M. (2018). Evaluating the Effectiveness of the Rural Minimum Living Standard Guarantee (Dibao) Program in China. China Economic Review (Amsterdam) .

https://doi.org/10.1016/j.chieco.2018.07.010

\section{Published in:}

China Economic Review (Amsterdam)

\section{Citing this paper}

Please note that where the full-text provided on Manchester Research Explorer is the Author Accepted Manuscript or Proof version this may differ from the final Published version. If citing, it is advised that you check and use the publisher's definitive version.

\section{General rights}

Copyright and moral rights for the publications made accessible in the Research Explorer are retained by the authors and/or other copyright owners and it is a condition of accessing publications that users recognise and abide by the legal requirements associated with these rights.

\section{Takedown policy}

If you believe that this document breaches copyright please refer to the University of Manchester's Takedown Procedures [http://man.ac.uk/04Y6Bo] or contact uml.scholarlycommunications@manchester.ac.uk providing relevant details, so we can investigate your claim.

\section{OPEN ACCESS}




\section{Accepted Manuscript}

Evaluating the effectiveness of the rural minimum living standard guarantee (Dibao) program in China

Nanak Kakwani, Shi Li, Xiaobing Wang, Mengbing Zhu

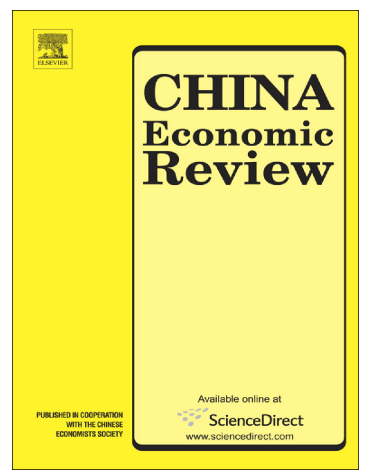

PII:

S1043-951X(18)30100-7

DOI:

doi:10.1016/j.chieco.2018.07.010

Reference:

CHIECO 1204

To appear in:

China Economic Review

Received date:

5 November 2017

Revised date:

12 June 2018

Accepted date:

28 July 2018

Please cite this article as: Nanak Kakwani, Shi Li, Xiaobing Wang, Mengbing Zhu, Evaluating the effectiveness of the rural minimum living standard guarantee (Dibao) program in China. Chieco (2018), doi:10.1016/j.chieco.2018.07.010

This is a PDF file of an unedited manuscript that has been accepted for publication. As a service to our customers we are providing this early version of the manuscript. The manuscript will undergo copyediting, typesetting, and review of the resulting proof before it is published in its final form. Please note that during the production process errors may be discovered which could affect the content, and all legal disclaimers that apply to the journal pertain. 


\title{
Evaluating the Effectiveness of the Rural Minimum Living Standard Guarantee (Dibao) Program in China
}

\author{
Nanak Kakwani ${ }^{\text {a, b }}$, Shi Li $^{\mathrm{a}}$, Xiaobing Wang ${ }^{\mathrm{c}, \mathrm{d},}$ and Mengbing $\mathrm{Zhu}^{\mathrm{a}}$
}

${ }^{\mathrm{a}}$ China Institute for Income Distribution, Beijing Normal University, No. 19, XinJieKouWai St., HaiDian District, Beijing 100875, China

${ }^{\mathrm{b}}$ School of Economics, The University of New South Wales, Sydney, NSW 2052, Australia

${ }^{c}$ Department of Economics, The University of Manchester, Oxford Road, Manchester M13 9PL, UK

${ }^{\mathrm{d}}$ School of Economics, Renmin University of China. HaiDian District, Beijing, China

* Corresponding author: Department of Economics, The University of Manchester, Oxford Road, Manchester M13 9PL, UK.

Email addresses: n.kakwani@unsw.edu.au (N. Kakwani), lishi@bnu.edu.cn(S. Li), Xiaobing.Wang@manchester.ac.uk (X.Wang), mengrubing-004@163.com (M. Zhu). 
Abstract

China's Rural Minimum Living Standard Guarantee program (Dibao) is the largest social safety-net program in the world. Given the scale and the popularity of Rural Dibao, it is necessary to rigorously evaluate it so that policymakers know the extent to which the program meets its intended objective of reducing poverty. This paper develops some new methods and uses data from the 2013 Chinese Household Income Project (CHIP2013) to examine the targeting performance of the rural Dibao program. The paper has found that the Rural Dibao program suffers from very low targeting accuracy, high exclusion error, and inclusion error, and yields a significant negative social rate of return. It discusses possible causes and argues that the fundamental mechanism has to be redesigned to increase the effectiveness of the program. The paper makes some recommendations to reform Dibao that will significantly improve targeting and reduce the cost of running the program. That will help China to achieve its goal of eradicating extreme poverty by 2020 .

JEL Classification: O11, 012, 023

Keywords: Dibao, Policy Effectiveness, Poverty Reduction, Social Rate of Return, China

Acknowledgement

The authors would like to thank the editors of this journal Cheryl Long and Xiaobo Zhang, the anonymous reviewers, and Binkai Chen, Quheng Deng, Indranil Dutta, Chuliang Luo, Xuezheng Qin, Kunal Sen, Hyun H. Son, Yangyang Shen, Haiyuan Wan, Ximing Yue, Peng Zhan, Shenghao Zhu, and seminar and conference participants at Asia Development Bank, Beijing Normal University, University of Manchester, Renmin University, The 2018

Chinese Economic Association (Europe/UK) China conference at Peking University, for useful comments and suggestions. 


\section{Introduction}

A growing number of developing countries are investing in a variety of social programmes to improve the welfare of people, particularly those who are poor and vulnerable. These programmes have become an essential pillar of economic development policies. The number of targeted programmes has increased manifold in developing countries. For example, Coady, Grosh, and Hoddinott (2004) have listed 85 programmes in 36 countries. According to a World Bank report, The State of Social Safety Nets 2015, as many as 1.9 billion people are beneficiaries of safety net programmes (Kakwani and Son 2016). By providing income to the poor or those who face a probable risk of falling into poverty, in the absence of the cash or in-kind transfers, such successful programmes reduced poverty and increased social cohesion and welfare.

China's minimum living standard guarantee programme (Dibao) is the largest social safety-net programme in the world. The programme was introduced in urban areas in the 1990s and was considered to be very useful in reducing urban poverty. The Chinese government extended the Dibao programme to rural areas in the early 2000s in the hope of alleviating the poverty and improving the livelihoods of the poor in the countryside. Given that poverty in China concentrates in the rural areas, the extension of Dibao to rural areas could have a significant impact on poverty reduction and equality improvement. In 2013, rural Dibao provides cash benefits to 29.31 million households covering 53.88 million individual beneficiaries according to Ministry of Civil Affairs (MOCA, 2014) ${ }^{1}$.

Rural and urban areas have separate Dibao programmes run by their respective local authorities; different regions have a distinct Dibao line, qualifying criteria and ways of distribution. It is imperative to know the impact and effectiveness of this programme. However, there is almost no evaluation of the programme in the existing literature. Golan et al. (2017) provide good descriptive analysis of the programme and some preliminary evaluation using the data from 2007 to 2009 when the programme was in its early stage.

Given the scale and the popularity of the rural Dibao, rigorously evaluation can demonstrate the extent to which the programme meets its intended objective of reducing poverty, thus being able to reduce wasteful spending, increase target accuracy and improve policy effectiveness.

This paper examines the effectiveness of the Dibao programme in China, using the 2013 Chinese Household Income Project (CHIP2013). It finds low targeting accuracy, and large inclusion and exclusion errors, along with a negative social rate of return. Although this paper is Chinafocused, the findings would be of interest to development economists working in the area of social protection in other developing countries.

\footnotetext{
${ }^{1}$ It is noted that the number of beneficiaries from our data is slightly smaller than this official data.
} 
This paper proposes several methods for assessing the effectiveness of the government programme and applies these methods on China's Dibao. It provides a comprehensive empirical evaluation of the rural Dibao programme. It is part of a bigger study that the authors will undertake to enhance understanding of poverty and inequality reduction in theory and improve the targeting and targeting efficiency of the social programme in practice.

Targeting is a means to improve programme efficiency so that programme objectives of maximizing poverty reduction can be achieved with minimum cost. There are two distinct issues in designing targeted programmes; the first is identifying the deserving beneficiaries who are the neediest, and the second is deciding the amount of transfers they receive so that their minimum basic needs are met. Accordingly, targeting efficiency is judged by two kinds of targeting methods that we derive from (i) beneficiary incidence and (ii) benefit incidence. We evaluated the rural Dibao using both beneficiary and benefit incidence analyses.

Cost is necessary for any social programme. Programmes ought to be judged based on how much they contribute to a reduction in poverty in their respective operational costs. In the literature, many poverty measures have been developed having different welfare implications. Among them, the class of poverty measures proposed by Foster, Greer, and Thorbecke (1984) (popularly known as the FGT poverty measures) is the most widely used. We evaluate the Dibao using the idea of the social rate of return (SRR). In calculating SRR, we use social welfare functions that incorporate normative judgments implicit in the FGT poverty measures. Low or negative social rates of return signify that the programme is not achieving its objective of reducing poverty with minimum cost.

We have organized the paper as follows: Section 2 provides a critical review of several targeting indicators. It also presents some new evaluation indicators. Section 3 provides a brief discussion of China's Dibao programme. Section 4 discusses the evaluation methodology explaining household welfare measures and poverty line used. Section5 presents our initial evaluation results analyzing the possible causes and consequences. Section 6 discusses the impact of Dibao on poverty reduction. Section 7 provides a new methodology for evaluating Dibao using the idea of the social rate of return (SRR). Finally, Section 8 concludes and discusses policy implications and recommendations.

\section{Targeting Indicators}

The primary challenge in designing social programmes is exact information about people's economic situations is not known. In the absence of such information targeting methods are used so that the poorest and most vulnerable members of society receive the maximum benefits. Targeting is a means of reaching the poor. Targeting indicators provide an evaluation of the existing programmes so that policymakers know if the current programmes meet the intended objectives of maximizing poverty reduction with minimum cost. 
This paper provides a detailed evaluation of China's Dibao programme using the following most comprehensive set of targeting indicators.

Ravallion (2009) concluded that standard targeting indicators are uninformative, or even deceptive, about the impact of programmes on poverty and cost-effectiveness in reducing poverty. He arrived at this conclusion without exploring the welfare implications of targeting indicators. We show that all targeting indicators proposed in the literature have a meaningful interpretation regarding the SRR.

\subsection{Correlation between poverty status and selection of beneficiaries}

Suppose $N$ is the total population of individuals, and among them, $N_{p}$ are the poor, and the headcount ratio of poverty is given by:

$$
H=\frac{N p}{N}
$$

Assume that $N_{b}$ are ry in the population is given by:

$$
B=\frac{N_{b}}{N}
$$

If perfect information about the poor was available, then all recipients of the programme will be poor. We do not have this information in practice. Suppose among $N_{b}$ beneficiaries, $N_{b p}$ are poor, and the remaining $\left(N_{b}-N_{b p}\right)$ are the non-poor beneficiaries. The probability of selecting a beneficiary among the poor is given by:

$$
B_{p}=\frac{N_{b p}}{N_{p}}
$$

Moreover, similarly, the probability of selecting a beneficiary among the non-poor is given by:

$$
B_{n}=\frac{\left(N_{b}-N_{b p}\right)}{\left(N-N_{p}\right)}
$$

If there is no association between the actual poor and selection of a beneficiary, then the probability of choosing a beneficiary among the poor must be equal to the probability of selecting a beneficiary among the non-poor. Alternatively, the poor are as likely to be chosen as the non-poor, in which case $B_{p}=B_{n}$. We may characterize this situation as having no information as to who the poor are, so everyone has the same probability of being selected in the programme. 
A programme may be classified as pro-poor if the probability of selecting a beneficiary among the poor is higher than that among the non-poor, i.e., when:

$B_{p}-B_{n}>0$.

Programmes should be designed they are pro-poor: the poor are more likely to be selected in the programme than the non-poor. The degree of pro-poorness can be measured by how much higher the probability is of selecting a poor person in the programme to the probability of selecting a non-poor person in the programme, which is as measured by the pro-poor index:

$\gamma=B_{p}-B_{n}$

(Equation 1)

In the case of perfect targeting, only the poor are selected as beneficiaries, and all non-poor are completely left out, which can happen only if $B_{p}=1$ and $B_{n}=0$. This gives the maximum value of pro-poor index $\gamma$ equal to 1 . The maximum value of $\gamma$ cannot be attained unless the proportion of beneficiaries in the programme is exactly equal to the proportion of poor, i.e., $B=H$. If $B<H$, in that case, some poor will be left out of the programme and some non-poor will be included in the programme i.e. $B_{p}<1$ and $B_{n}>0$. Similarly, if $B>H$, then all poor can be included in the programme but all non-poor cannot be excluded, i.e. $B_{p}=1$ and $B_{n}>0$. Thus, the maximum value of $\gamma$ cannot be attained unless $B=H$.

A programme is said to mismatch if $B \neq H$. In almost all targeted programmes the researchers of this paper have encountered, $B$ is never equal to $H$. An important implication of this is that even if perfect information about the poverty status of households is available (which household is poor and which is non-poor), the power of a programme is much diminished.

There are two kinds of mismatch. The most common mismatch is when $B<H$. The cost of any targeted programme depends on what proportion of beneficiaries are included in the programme; the larger $B$ is, the higher the cost of the programme . Most governments in developing countries have budget constraints, so there is always a tendency to design programmes that have $B$ as small as possible. In this situation, the targeting efficiency cannot be evaluated by the propoor index given in formula (1). When there is a mismatch, a programme can be evaluated by measuring the association between poverty status and selection of beneficiaries. Using a $2 \times 2$ contingency table, we propose the following test statistics:

$\varphi=\left(B_{p}-B_{n}\right) \sqrt{\frac{H(1-H)}{B(1-B)}}$

(Equation 2)

When $\varphi=0$, it implies that there is no association between poverty and selection of beneficiaries, or in other words, the poor are as likely to be selected in the programme as the non-poor. In this 
case, $N \varphi^{2}$ follows a $\chi^{2}$ distribution with 1 degree of freedom. This result allows us to test the null hypothesis of no association between poverty status and selection of beneficiaries.

The larger the value of $\varphi$, the higher the association between poverty status and selection of beneficiaries. As shown above, this statistic is also related to the degree of pro-poorness of the programme; the larger the value of $\varphi$, higher the pro-poorness of the programme. If the value of $\varphi$ is found to be statistically insignificant, the programme is not explicitly targeted to the poor. An implication of such a result is that the programme will have no significant impact on poverty reduction.

\subsection{Exclusion Error and Leakage}

Exclusion error and leakage are commonly used indicators to evaluate targeting efficiency. The exclusion error is the percentage of poor whom we exclude from the programme and is given by:

$E=1-B_{p}$

(Equation 3)

The exclusion error informs what percentage of eligible persons we exclude from the programme. It is a measure of horizontal inequity when we do not treat individuals in the same economic circumstances equally.

We define leakage as the percentage of all beneficiaries who are not poor (or not eligible for the programme).

$L=\frac{B-H B_{p}}{B}$

(Equation 4)

This equation measures the resources going to unintended beneficiaries of the programme.

Exclusion error and leakage are related such that

$L=1-\frac{H}{B}(1-E)$.

(Equation 5)

If the probability of selecting a beneficiary is equal to the headcount ratio of poverty $(B=H)$, then leakage is equal to exclusion error $(L=E)$. If $B<H, L<E$ and similarly, if $B>H$, then $L>E$. The difference between leakage and exclusion error is an indicative of the degree of mismatch in the programme.

While both errors are undesirable, we cannot simultaneously reduce them. If we increase the number of beneficiaries as the programme expands, then we can reduce the exclusion error but then the leakage increases. A reduction in one error may cause the other to increase. There is no simple formula to evaluate how well-targeted a programme is. There might be a trade-off between the two errors; therefore, some normative judgment is needed in evaluating the programme. 


\subsection{Benefit Incidence}

Benefit incidence is concerned with how the programme distributes total transfers among the poor and the non-poor. Suppose $B$ is the average number of beneficiaries in the population and $\beta$ is the average transfers given to each beneficiary, then the average benefits per person in the population will be given by $\bar{b}=\beta B$.

Similarly, if $\beta_{p}$ and $\beta_{n}$ are the average transfers given to each beneficiary among the poor and the non-poor, respectively, then $\bar{b}_{p}=\beta_{p} B_{p}$ and $\bar{b}_{n}=\beta_{n} B_{n}$ are the average benefits per person among the poor and the non-poor, respectively. Following Kakwani and Son (2016), we then have the relationship:

$\bar{b}=H \bar{b}_{p}+(1-H) \bar{b}_{n}$

which can be written as:

$\beta B=H \beta_{p} B_{p}+(1-H) \beta_{n} B_{n}$

Leakage of benefits (or resources) is an essential targeting indicator, which we define as the proportion of total transfers going to the non-poor:

$l=\frac{\beta B-H \beta_{p} B_{p}}{\beta B}$

(Equation 6)

Recall that $L$ is the proportion of the total number of beneficiaries selected from the non-poor. The relationships between $l$ and $L$ is shown by:

$l=L+\frac{H B_{p}}{\beta B}\left(\beta-\beta_{p}\right)$

(Equation 7)

Which implies that if $l>(<) L$, then $\beta>(<) \beta_{p}$. That is, if the leakage of benefits is higher (lower) than the leakage of beneficiaries, the benefits per beneficiary will be higher among the non-poor (poor). This suggests that the targeting efficiency should be judged on two accounts: (i) how beneficiaries are distributed among the poor and the non-poor and (ii) how much of the benefits are given to the poor and non-poor beneficiaries. If the poor and non-poor beneficiaries receive exactly the same benefits, the leakage of benefits will be exactly the same as the leakage of beneficiaries. The difference between leakage in benefits and leakage in beneficiaries indicates the degree of inequity in the benefits given to beneficiaries among the poor and the non-poor, respectively.

\subsection{Universal Basic Income}

A universal basic scheme is a form of social security in which all individuals in the society receive certain transfers from the government. This idea ultimately gets rid of targeting the poor for all social transfers. The poor and rich are all equal beneficiaries of social programmes. 
Since the universal basic scheme includes all the poor, the exclusion error is always zero, but there will be high leakage. The probability of being a beneficiary is the same for the poor and the non-poor, expressed as $B_{p}=B=1$, which on substituting in formula (4) gives the leakage $L=(1-H)$. For instance, in China, the official estimate of the percentage of poor is about $10 \%$, which means that if a universal basic scheme is introduced in China, about $90 \%$ of beneficiaries will be non-poor. Similarly, for most social security programs, all beneficiaries receive exactly the same amount, the leakage of benefits or resources will also be about $90 \%$. $^{2}$ Thus, universal basic income schemes completely eliminates exclusion errors but it introduces exceptionally large leakage to the non-poor. This scheme is based on no targeting; it can be used as a benchmark to evaluate Dibao. Since this paper seeks to know how Dibao performs in reducing poverty relative to the universal basic income scheme, the same cost of the programme must be kept, and the benefits received by a person with income $x$ will be given by:

$b(x)=\bar{b} \quad$ for all $x$

(Equation 8)

Where $\bar{b}$ is the average transfers going to the population. We calculate the incidence of poverty using the transfer scheme in formula (6), which provides a benchmark under the universal basic income.

\subsection{Perfect Targeting}

If the poor can be correctly identified and given precisely the difference between the income and poverty line, then perfect targeting results. Under this scenario, there will be no exclusion error and leakage in both beneficiaries and benefits. The maximum reduction in poverty will be achieved. We may describe perfect targeting as:
$b(x)=k(z-x)$ if $x<z$
(Equation 9)
$b(x)=0 \quad$ if $x \geq z$

Per capita cost of such a programme, (excluding administrative cost) will be given by:

$\overline{b_{f}}=k\left(z H-\mu^{*} H\right)$

Where $\mu$ is the mean income. Since we want to assess the performance of Dibao against perfect targeting as a benchmark, we should keep the same per capita transfers to beneficiaries. We determine $k$ so that $\bar{b}_{f}=\bar{b}$, which gives:

$k=\frac{\bar{b}}{H\left(z-\mu^{*}\right)}$

\footnotetext{
${ }^{2}$ For rural Dibao in China, beneficiaries do not always receive the same amount. There are several different levels of transfers to households with different economic circumstances.
} 
The incidence of poverty can be calculated under perfect targeting using the transfer scheme in formula (7), which provides a benchmark for assessing any programme.

\subsection{Social rate of return (SRR)}

In practice, investors make decisions about their investments by how much return they generate. We assess how good investment is by its rate of return. A similar approach may be adopted when we invest in social programmes.

Cost is a necessary component of any social assistance programme. Programmes ought to be judged based on how much social welfare they generate above their respective operational costs. Kakwani and Son (2016, Ch10) proposed a method for evaluating programmes using the idea of the social rate of return (SRR). In calculating SRR, we use a social welfare function that specifies normative judgments by assigning weights to different individuals.

We define the social rate of return (SRR) as the social welfare generated by a programme as a percentage of the cost of the programme. To measure the social rate of return, we need to specify a social welfare function that we measure in money metric. For instance, we should be able to say how much, as measured in a country's currency, the increase in social welfare is so that we can compare it with the cost of the programme measured in the same currency. Logically, social welfare generated by the programme should outweigh the operational cost of the programme.

Since the primary objective of Dibao programme is to reduce poverty, we should use social welfare functions that incorporate normative judgments implicit in some poverty measures. The FGT poverty measures (Foster, Greer, Thorbecke 1984) are most widely used to measure poverty. Kakwani and Son (2016, Ch3) and Kakwani et al (2018) have developed social welfare functions corresponding to the entire class of FGT poverty measures:

$W_{\alpha}=\mu-H z\left(\frac{\theta_{\alpha}}{H}\right)^{\frac{1}{\alpha}}$

(Equation 10)

Where $\theta_{\alpha}$ is the FGT class of poverty measures, which is the headcount ratio $(H)$ if $\alpha=0$, the poverty gap ratio if $\alpha=1$, and the severity of poverty ration if $\alpha=2$, and $\mathrm{z}$ is the poverty line. This is the social welfare measured in money metric, for instance, Yuan per year. The second term in the right hand side of this equation is the loss of social welfare caused due to the existence of poverty. This term depends on what poverty measure is used.

To calculate the SRR, we have to determine how much the programme increases social welfare. The change in social welfare due to the programme is given by:

$$
\Delta W_{\alpha}=\Delta \mu-z \Delta\left[H\left(\frac{\theta_{\alpha}}{H}\right)^{\frac{1}{\alpha}}\right]
$$


which is the social benefit of the programme. To calculate the SRR, we should compare the social benefit of the programme with its cost. There are two kinds of costs: (1) the amount of money transferred to beneficiaries and (2) the administrative cost. For simplicity, we can assume that administrative cost is proportional to the total transfers going to the household. This assumption may not always be valid because for any programme; there is a fixed initial cost when the programme starts and then there is a variable cost which depends on how many beneficiaries are selected and how much benefits transferred. The cost also depends on how intensive targeting is. If targeting is intense, it will generate higher social welfare, but then the administrative cost will also be higher. There is always a trade-off between the degree of targeting and administrative cost. The idea of SRR incorporates such trade-offs. In the measurement of the impact of a programme on poverty, it is essential to calculate the administrative cost, which takes account of both fixed and variable. The targeting literature seldom uses administrative cost in evaluating the efficacy of social programmes.

Suppose $T$ is the total transfers going to the beneficiaries and $\in$ is the administrative cost per Yuan transferred to beneficiaries, then the total programme cost will be $(1+\epsilon) T$ which yields the SRR:

$S R R=\frac{\Delta W_{\alpha}}{(1+\epsilon) T}-1$

(Equation 12)

For instance, a hypothetical programme generates the total welfare equal to 30 Billion Yuan per year and the total transfers to going to beneficiaries is 19 Billion Yuan per year. Moreover, if 5\% of the transfers is the administrative cost, then the SRR of return will be approximately $50 \%$, implying a social investment of 1 Yuan generates social welfare of about 1.50 Yuan.

We must emphasize that the assumption of the administrative cost being a fixed proportion of total transfers is too simplistic. The relationship between administrative cost and total transfers is not linear. When a programme starts, it requires developing a social infrastructure which requires sizeable fixed cost, but over time, the variable cost becomes more important. When several local governments run the programme, we cannot assume that all will have the same levels efficiency. The calculation of administrative cost is highly complex but to calculate it accurately requires taking into account of all its complexities.

We can calculate the SRR under the three alternative transfer schemes:

(i) Actual transfers are under the programme.

(ii) Transfers are under the universal basic income (no targeting).

(iii) Transfers are under perfect targeting.

A comparison of these three SRR provides a new evaluation method of social programmes. 


\subsection{The relationship between targeting indicators and the SRR}

The World Bank report, The State of Social Safety Nets 2015, has evaluated almost all the safety net programmes in the world. Its evaluation was conducted using a social welfare function that focuses on the poorest $20 \%$ of the population. The SRR based social welfare function focused on the poorest $20 \%$ population is given by:

$S R R=\frac{(1-l)}{0.2(1+\epsilon)}$

where $l$ given in (6) is an important targeting indicator. This equation demonstrates that for a fixed administrative cost, the SRR is a monotonically decreasing function of leakage: the larger (smaller) the leakage, the smaller (larger) the SRR. Similarly, we can show that all targeting indicators are related to an implicit social welfare function, which can meaningfully incorporate some facets of poverty. Thus, Ravallion's (2009) conclusion that the standard targeting indicators are uninformative or even deceptive is questionable.

\section{The minimum living standard guarantee programme in China: Dibao}

The minimum living standard guarantee programme (Dibao) is a significant component of the social assistance programme in China. It was launched in the 1990s in the more developed urban regions in China to assist some urban workers during the period of economic reform and structural change. The Dibao programme aims to provide cash support to help those whose income is lower than a certain level and has played a significant role in poverty reduction and social stability improvement in urban China. (Ravalion, 2006; Wang, 2007)

The success of the Dibao programme in urban areas also led to a nationwide trial of the Dibao programme in the rural areas from 2007. Rural and urban Dibao programmes are similar in design, but with different minimum living standards among local areas. The income threshold level (Dibao line) varies across regions and is different between urban and rural areas. The income threshold is higher in urban areas than in the rural areas. Golan et al. (2017) provided a detailed description of rural Dibao.

Both central and local governments provide the funding for the programme. The central government allocates funds for a province based on an estimation of the number of people in poverty and the extent of their poverty. Provincial governments then give the funds to its subordinate, until it gets into the hands of those in need. 
For a household to get the Dibao in the local area, a household registration (Hukou) is required. In principle, a household is eligible to apply for the Dibao assistance as long as their income is lower than the threshold level in the local area; households do not have to satisfy any other conditions. The amount of cash transfer received is usually the difference between the income threshold level and the household's income. Since actual household incomes are not known to officials, there will be a possibility of a high degree of inequity in the distribution of cash transfers.

Implementation remains decentralized. The local authorities determine eligibility thresholds (Dibao line), beneficiary selection, and transfer payment amounts. The income threshold level set by the local governments usually depends on the economic conditions of local areas such as the consumption level, capacity, and funding for the local areas.

Unlike the rural poverty line which is set by the central government, the Dibao thresholds are set by local governments and vary across regions. This is because part of the Dibao funding is from local government. Regions with better economic conditions tend to have a higher income threshold level than those with worse economic conditions. Poor counties tend to have lower Dibao thresholds and transfers than do affluent counties.

Due to the fiscal interactions among regions, local governments tend to reduce the level of minimum living standard guarantee in its jurisdiction if there is a decrease in the minimum living standard in neighboring regions. Thus, regions race to the bottom of welfare spending expenditure. (Zhang et al., 2016). We discuss different Dibao lines across regions in the appendix.

First, it should be noticed that Dibao line and poverty line are not unified. According to Ministry of Civil Affairs, the yearly Dibao line for rural residents is 2433.9 yuan, which is less than the calculated poverty line (\$2736), so given the existing difference, and based on the authors' sample, the group of people below the poverty line is not necessarily in the group who enjoy the Dibao, hence, the leakage rate will be overestimated.

The management of Dibao is highly decentralized, based on a de facto quota system. In practice, authorities estimate the number of poor in a region and then distribute the fund accordingly. For a given amount of funds, county-level officials decide the Dibao line and accordingly, distribute certain funds to their subsidiaries up to the villages, where local cadre or villagers decide who should get the money. It is possible that a more affluent village gets more quota than it needs and another region may get much less, which can only barely cover the extremely poor.

National policy permits local government to make use of a range of information to evaluate eligibility in practice. For instance, this might include not only household income, but also household structure, the presence of household members who are unable to work or are disabled, household assets, or housing conditions. 
Many local governments have developed their own criteria which are often different. For example, many places look at five aspects in deciding whether a household should be included: 1) whether the family house is of good quality and good status; 2) whether there is enough food; 3) whether there is a student in the household that needs financial support; 4) whether family members have good skills; 5) whether the household has any members who are disabled, or suffer from severe illnesses. However, there are certain discrepancies among different regions. The discretionary power to local governments may create corruption.

At the village level, it is often the case that Dibao households were not means tested, but democratically decided by villagers based on their perception. For instance, in some places, the recipients are selected by counting off incomes ranked from highest to lowest and choosing from the poorest, while in other places; villagers decide the allocation of Dibao through voting.

In our field studies and interviews with many local officials and villagers, we found it is often the case that villagers gather together to discuss and decide who should receive Dibao. Very often, it is easy to identify a couple of extremely poor households who should get the money, but difficult to settle the households who should get the rest of the money. If there are more households that are equally poor than the number of the households that can be supported by Dibao, then villagers often decide that some households would rotate yearly to receive Dibao subsidy.

When this rotation takes place, our 2013 data would only pick those who get Dibao in that year and would have no information about the others who might have or will benefit. Thus, the targeting shown from our data may not be accurate.

To summarize, the transfers that are given to beneficiaries also vary across counties and there exists no uniform criterion for identifying who should get Dibao. The targeting measured by income and consumption in our analysis will show these discrepancies.

\section{Evaluation methodology}

The evaluation of Rural Dibao carried out is based on the fifth round of the Chinese Household Income Project (CHIPs) covering rural households in the year 2013 (CHIP 2013) These surveys were carried out by the China Institute for Income Distribution at the Beijing Normal University.

The rural survey sample contains more than 10,000 households in 12 provinces and two province-level municipalities, which are representative of China, across eastern, middle and western regions. These are Beijing, Liaoning, Jiangsu, Shandong, Guangdong, Shanxi, Anhui, Henan, Hubei, Hunan, Gansu, Sichuan, Chongqing, and Yunnan. The sample is a subset of the 
National Bureau of Statistics (NBS) annual rural household survey (approximately 65,000 rural households). ${ }^{3}$

The CHIPs surveys are the best publicly available data source on Chinese household income and expenditures (Riskin, Zhao, and Li, 2001). These data remain the only source of household level information on income and other individual and household characteristics that are representative of China as a whole. (Gustafsson, Li, and Sicular, 2008).

The primary objective of social assistance programmes is to reduce poverty. It is therefore essential to be able to identify the genuine poor who need help from the government. To identify the poor objectively, we need to know a metric of household welfare, which accurately informs the economic situation of households of different size. In most countries, per capita income is used to measure household welfare. The household welfare should include all contributing income components. The households also make transfers to other households and pay taxes which do not contribute to their welfare, so we have to deduct these expenditures from their gross income. Household welfare is thus determined by disposable income, which is the net income available to households for consumption.

Many developing countries use per capita expenditure as a measure of household welfare. In these countries, it is difficult to accurately measure income due to the existence of a significant informal sector. However, from the welfare point of view, consumption is regarded as the better basis for determining who is poor who is not. This is because in any given month or year there is much greater fluctuation in income than in actual household consumption, Households tend to smooth their consumption across periods by saving or dissaving as needed. Households' consumption during the survey period provides a better measure of their permanent standard of living than their current income.

The CHIPs survey provided both income and consumption. Since there are both pros and cons of using income or consumption as measures of household welfare, we have used both as a basis for evaluating the Dibao programme. Since the cost of living varies across provinces, we adjusted welfare measures by deflating the incomes by the spatial price indices for different provinces of China (numeracies equals national average consumption basket). Thus, our two alternative household welfare measures are the real per capita disposable household income and real per capita household consumption.

Measuring poverty among individuals requires the welfare of individuals. To derive an individuals' welfare, we assume that all individuals belonging to the same household experience

\footnotetext{
${ }^{3}$ The National Bureau of Statistics (NBS) surveys household income since 1950s and has a large sample size and thus better representation. For example, NBS surveyed about 74,000 rural households from 869 counties and about 66,000 urban households in 474 cities in 2010. CHIP surveys a subsample of these households. However, official data are unavailable to the public. Gustafsson et al (2014) presented official data on household income as well as seven researcher initiated databases and commented on their characteristics.
} 
the same standard of living. If we identify a household as poor, then all individuals belonging to this household are also identified as poor. This assumption is common in the measurement of poverty because the intra-household distribution of household resources is not known. The poverty estimates presented here, therefore, relate to the poverty among individuals (not households).

An evaluation must be carried out against a benchmark. As Dibao is a highly decentralized programme in which each local authority determines eligibility thresholds and transfer payments, each county has its poverty line for identifying the poor. Should Dibao be evaluated separately across each county? A problem with this approach is that counties do not have clear criteria: they do not use a defined poverty line to identify the beneficiaries; they make their decisions on an ad hoc basis. Since Dibao is a national programme, this paper focuses on evaluate Dibao using a national benchmark. An apparent national benchmark for our purpose is a national poverty line for the rural areas.

We have used the rural official poverty line of 2,736 Yuan per person per year for 2013 which is about $28 \%$ of the average per capita real income. The Purchasing Power Parity (PPP) exchange rate for the Chinese Yuan per dollar was 3.545 in 2013, which gave the per person per day official poverty line equal to \$2.11 in 2011 PPP. The World Bank set the poverty line for the extremely poor.at $\$ 1.90$ in 2011 PPP Thus, the Chinese official poverty line is about $11 \%$ higher than the World Bank's poverty line for the extremely poor. The Chinese poverty line rate is reasonable, given the Chinese level of economic development.

\section{Evaluation of Dibao (2013)}

Table 1 presents the estimates of various targeting indicators (discussed in Section 2). As pointed out, this paper bases evaluation on two alternative welfare measures: (i) per capita real disposable income and (ii) per capita real household consumption. The estimates of targeting indicators are presented separately for the two welfare measures. Based on the CHIP survey, the total rural population of China in 2013 was 620.22 million. According to the 2014 Statistical Yearbook published by the National Bureau of Statistics, the total rural population in 2013 was around 630 million, which is close to the estimate based on the CHIP data.

Based on the Chip survey, per capita real disposable income in 2013 prices is equal to Yuan 9,850 per year whereas per capita real household consumption is estimated equal to Yuan 7,731 per year. Household consumption is approximately $78 \%$ of the household disposable income. The two welfare measures also have different inequality as measured the Gini index. The Gini index of per capita consumption is at $36.44 \%$, which is much lower than that for the per capita 
disposable income at $40.73 \%$. It is quite common that inequality of consumption welfare is lower than that of income welfare.

Although we have used the same poverty line for the two welfare measures, different poverty estimates have resulted. The percentage of poor based on per capita disposable income is $10.12 \%$, while that for per capita consumption is $9.40 \%$. The consumption poverty is lower than the income poverty because consumption has lower inequality than income in China. In most situations, poverty gap and severity of poverty have lower values than the percentage of poor because they take account of not only who are the poor but also how much poor they are.

We found unusual estimates of poverty gap and severity of poverty, whose values based on per capita income are $4.85 \%$ and $13.33 \%$, respectively. The main reason for these unusual estimates is that approximately 70 sample households in the CHIP had high negative incomes. Although negative income is typical in many household surveys, such high negative incomes are somewhat unusual. All the negative incomes have been retained in our analysis because it was unknown whether households with such high negative incomes were genuinely poor or they were not poor but had temporary setbacks. The main advantage of using consumption welfare is that it cannot have negative values.

Poverty gap and severity of poverty on consumption-based welfare are $1.98 \%$ and $0.63 \%$, respectively, which seems reasonable when compared with estimates obtained from many other countries. The number of poor in rural China is 62.79 million based on per capita disposable income and 58.29 million based on per capita consumption.

As discussed in Section 2, exclusion error and leakage are commonly used indicators to evaluate targeting efficiency. The exclusion error is the percentage of poor that are excluded from the programme. Meanwhile, leakage is the percentage of all beneficiaries who are not poor (or not eligible for the programme). Therefore, leakage measures the resources going to unintended beneficiaries of the programme.

Of 62.79 million poor, only 7.61 million were programme beneficiaries, which mean that 55.18 million poor were not included in the programme. Thus, Dibao excludes $87.89 \%$ of poor from receiving any benefit, which is a very high degree of exclusion error. Exclusion error based on per capita consumption is $86.6 \%$, which is slightly lower but still very high in comparison with many international social assistance programmes (Kakwani 2016). Thus the programme is generating a high degree of horizontal inequity.

Of the total number of 42.72 million beneficiaries ${ }^{4}, 35.11$ million are non-poor, which equates the leakage of beneficiaries in the programme to $82.2 \%$. Leakage is also very high at $82.07 \%$

\footnotetext{
${ }^{4}$ As mentioned earlier, the number of Dibao beneficiaries from our data is 42.72 million, which is smaller than the official data of 53.821 million provided by Ministry of Civil Affairs (MOCA 2014). This discrepancy may be due the sample representation of MOCA and/or CHIP. We checked many indicators in table 1 against the China Family
} 
when we use per capita consumption as a welfare measure. ${ }^{5}$ High leakage of this magnitude amounts to substantial resources going to unintended beneficiaries of the programme.

Both exclusion error and leakage are incredibly high in comparison with international standards. It seems that in the selection of beneficiaries, the programme did not use the poverty status of individuals. In Section 2 we developed a test statistic $\varphi$, which measures the association between poverty status and selection of beneficiaries. When $\varphi=0$, it implies that there is no association between poverty and selection of beneficiaries - or in other words, the poor are as likely to be selected in the programme as the non-poor. It was shown that $N \varphi^{2}$ is distributed as a $\chi^{2}$ distribution with one degree of freedom. This result allows us to test the null hypothesis of no association between poverty status and selection of beneficiaries.

From the data, $\varphi$ for the Dibao is calculated to 0.07 on income-based welfare measure and 0.08 on consumption-based welfare, both of which are not statistically significant at the $5 \%$ level of significance. Thus, we cannot reject the hypothesis of no association, whatever welfare measure we use. We may thus conclude that in the selection of individuals, the programme did not use the poverty status of the individual; the programme selected beneficiaries by factors other than their poverty status. 67

Benefit incidence is concerned with how the programme distributes total transfers among the poor and the non-poor. The average transfer from Dibao to the whole population is Yuan 31.96 per person per year. Multiplying this by the total rural population of 620.22 million equates the total transfer cost of the programme to 19.8 billion per year. Additionally, there may be some administrative costs of running the programme. Although we do not know the exact amount of

Panel Studies (CFPS). However, the results from CFPS 2014 survey showed that the number of low income individuals were extraordinarily high, which casts doubt on its national representativeness. The household surveys by National Bureau of Statistics (NBS) have a large sample size but are unavailable to the public. In order to better understand earnings, the distribution of household income, and the effectiveness of the social programs, China should be make an effort to make the official survey data and relevant administrative data available to researchers. ${ }^{5}$ Using CFPS 2012 data and the national poverty line, Han and Gao (2017) conclude that the rural Dibao program has large targeting errors, showing the leakage and exclusion rates as $76 \%$ and $62 \%$, respectively.

${ }^{6}$ As discussed in section 3, in practice, Dibao program selects beneficiaries not only according to household income levels, but rather uses various kinds of multi-dimensional poverty criteria to determine who should receive Dibao benefits. Thus, it is not surprise that we observe larger leakage and exclusion errors in 2013, since these indicators used only income as a benchmark.

${ }^{7}$ It should also be noted that, as discussed in section 3 and in the appendix, the Dibao line and poverty line are not unified, the Dibao line varies cross regions and Dibao lines in many poor regions are lower than the poverty line. So given the existing difference, some people in poor regions below the poverty line may not necessarily be included in the Dibao program, and some people in richer regions may get Dibao despite the fact that their incomes are higher than the national poverty line. A calculation of leakage rates based on a single poverty line may include people who were intentionally left out of the program as a leakage. When use the county-level Dibao lines in 2013, we still get quite large leakage and exclusion errors which are $82.61 \%$ and $90.82 \%$, respectively. Other indicators may suffer similar problems due the non-uniformity of the poverty line and Dibao lines. However, we argue that if the purpose of Dibao is to target poverty, it should not use different Dibao lines across different regions. Golan et al. (2017) argue that in a world of perfect targeting, replacing local thresholds with a uniform threshold would reduce poverty. 
administrative cost of Dibao, we know its funding came from both the central government and local governments.

Official Statistics for China's Rural Dibao programme reported that the total transfers going to Dibao from all levels of government were approximately 87 Billion Yuan in 2013 (Golan et al 2017). Given the amount of actual transfers to beneficiaries is 19.8 billion, the non-transfer (or administrative) cost of the programme is approximately 67.2 billion - an extraordinary running cost which equates to the spending of Yuan 3.4 in administrative costs for every Yuan transferred to beneficiaries.

The average value of transfers being received by each beneficiary can be calculated by dividing the total transfers to the population by the number of beneficiaries. This results in an average transfers per beneficiary of Yuan 464.02 per year. However, as there are different numbers of poor and non-poor beneficiaries here will be different amounts of transfers per beneficiary. The average amount of transfers going to poor beneficiaries is calculated at Yuan 348.43 per year while the amount going to non-poor beneficiaries is Yuan 489.06 per year, demonstrating a significant inequity in the payment of programme benefits to the poor and non-poor. Thus, Dibao suffers from serious inequity in the distribution of benefits going the poor and non-poor, where on average, the poor beneficiaries receive much less than those non-poor beneficiaries who were not supposed to receive Dibao in the first place.

Leakage may also be defined as the percentage of total benefits going to the non-poor. This indicator measures the percentage of resources in monetary terms that are going to unintended beneficiaries. The number of non-poor beneficiaries in Dibao is equal to 35.11 million, and each non-poor beneficiary receives an amount of Yuan 489.06 which equates the total resources leaked to the non-poor to Yuan 17.37 billion. The total transfer cost of the programme is Yuan 19.8 billion. Thus, the percentage of total funds leaked out to the non-poor (the leakage rate of resources) is $86.63 \%$, This leakage is even higher than the leakage of beneficiaries which was calculated at $82.2 \%$. The leakage is $85.11 \%$ when welfare measured is per capita consumption, which is also high by any international standard. 
Table 1: Targeting indicators of China's Rural Dibao Programme 2013

\begin{tabular}{|c|c|c|}
\hline & Per capita real & Per capita real \\
\hline Targeting Indicators & disposable income & consumption \\
\hline Total Rural Population (million) & 620.22 & 620.22 \\
\hline Gini index: & 40.73 & 36.44 \\
\hline \multicolumn{3}{|l|}{ Poverty indicators } \\
\hline Official poverty line (Yuan per year) & 2736 & 2736 \\
\hline$\%$ of poor & 10.12 & 9.40 \\
\hline Poverty gap ratio $\%$ & 4.85 & 1.98 \\
\hline Severity of poverty $\%$ & 13.33 & 0.63 \\
\hline Number of poor(million) & 62.79 & 58.29 \\
\hline Number of non-poor (million) & 557.43 & 561.93 \\
\hline \multicolumn{3}{|l|}{ Welfare indicators } \\
\hline Per capita household welfare: Yuan per year & 9850 & 7731 \\
\hline Per capita household welfare of poor: Yuan per year & 1425 & 2160 \\
\hline Per capita household welfare of Non- poor: Yuan per year & 10799 & 8309 \\
\hline Per capita welfare of Dibao beneficiaries: Yuan per year & 6080 & 5382 \\
\hline \multicolumn{3}{|l|}{ Beneficiary Incidence } \\
\hline$\%$ of beneficiaries & 6.89 & 6.89 \\
\hline Number of beneficiaries(million) & 42.72 & 42.72 \\
\hline Number of poor included in Dibao (million) & 7.61 & 7.66 \\
\hline Number of poor excluded from Dibao (million) & 55.18 & 50.63 \\
\hline Exclusion error(\% of poor excluded) & 87.89 & 86.86 \\
\hline Number of non-poor included in Dibao (million) & 35.11 & 35.06 \\
\hline$\%$ of beneficiaries among the poor & 12.11 & 13.14 \\
\hline
\end{tabular}




\begin{tabular}{|l|l|l|}
\hline \% of beneficiaries among non-poor (inclusion error) & 6.30 & 6.24 \\
\hline Leakage ( \% of all beneficiaries from non-poor) & 82.20 & 82.07 \\
\hline Benefit incidence & & \\
\hline Average transfer in the population Yuan per year & 31.96 & 31.96 \\
\hline Average transfer among the poor Yuan per year & 42.20 & 50.63 \\
\hline Average transfer among the non-poor & 30.81 & 30.02 \\
\hline Total transfers going to beneficiaries per year (billion) & 19.8 & 19.8 \\
\hline Total transfers going to poor beneficiaries (billion) & 2.6 & 3.0 \\
\hline Total transfers going to non-poor beneficiaries (billion) & 17.2 & 16.9 \\
\hline Leakage: Proportion of total transfers going to non-poor\% & 86.63 & 85.11 \\
\hline Average transfer per beneficiary (Yuan per year) & 464 & 464 \\
\hline Average transfer per beneficiary among the poor & 348 & 385 \\
\hline Average transfer per beneficiary among the non-poor & 489 & 481 \\
\hline
\end{tabular}

\section{Impact of Dibao on poverty reduction}

The primary objective of Dibao is to reduce poverty. How much does the programme contribute to the poverty alleviation? To answer this question, we calculated poverty reduction with and without programme transfers going to beneficiaries. Table 2 presents the actual magnitude of poverty reduction separately for the two alternative welfare measures: per capita disposable income and per capita consumption. The programme contributes to a reduction in the percentage of poor by 0.42 percentage points when welfare measure is per capita real disposable income. The reduction in the percentage of poor is even higher at 0.63 percentage points when welfare measure is per capita consumption. It may be concluded from the results in Table 2 that Dibao does contribute to poverty reduction, but we cannot infer from this how effective the programme is in reducing poverty without a benchmark. Our benchmark is the universal basic income given to every resident with no targeting but keeping the same transfers to beneficiaries. Table 3 presents the magnitudes of poverty reduction under the universal basic income. 
Table 2: Contribution of Dibao to Poverty Reduction

\begin{tabular}{|l|l|l|}
\hline Poverty & Per capita real & Per capita real \\
\hline Measure & disposable income & consumption \\
\hline \% of poor & -0.42 & -0.63 \\
\hline Poverty gap ratio \% & -0.22 & -0.27 \\
\hline $\begin{array}{l}\text { Severity of poverty } \\
\%\end{array}$ & -0.20 & -0.16 \\
\hline
\end{tabular}

Comparing the magnitude of poverty reduction in Tables 2 and 3, we note that Dibao achieves greater poverty reduction when there is no targeting, that is when all individuals receive the same amounts of transfers but with the same total transfers going to beneficiaries. It is also noted that the difference in magnitudes of poverty reduction is minimal. Any programme that does not have targeting has the least administrative cost. As stated earlier in this paper, according to Golan $e t$ al. (2017), the total transfers going to Dibao from all levels of government was about Yuan 87 billion in 2013. The actual transfers sent to beneficiary households is estimated at approximately Yuan 19.8 billion (Table1), which results in the non-transfer cost of the programme of about 67.2 billion, an extraordinary running cost of the programme. Since Dibao did not make a significant contribution to poverty reduction compared to a no targeting scenario, Dibao 's targeting efficiency cannot be highly rated. It would then be better to replace Dibao with the universal basic income programme which would have almost negligible administrative cost. The main advantage of a universal basic income programme is that it has zero exclusion error and hence it does not suffer from horizontal inequity. Leakage of it will be about 90\%, but Dibao also has a high leakage rate of about $86 \%$. Thus, Dibao does not have much advantage over the universal basic income scheme. 
Table 3: Poverty Reduction under universal targeting

\begin{tabular}{|c|c|c|}
\hline Poverty & Per capita real & Per capita real \\
\hline Measure & disposable income & consumption \\
\hline$\%$ of poor & -0.30 & -0.50 \\
\hline Poverty gap ratio \% & -0.16 & -0.21 \\
\hline $\begin{array}{l}\text { Severity of poverty } \\
\%\end{array}$ & -0.14 & -0.12 \\
\hline
\end{tabular}

\section{Dibao's Contribution to Welfare and Its Social Rate of Return}

This section presents the results following the methods discussed in subsection 2.6. Tables 4 reports the value of social welfare calculated using equation (10), which takes into account the deprivation suffered by the population due to the existence of poverty. We report the contributions to social welfare according to equation (11) in Table 5. The social rate of return, which is the social welfare generated by a programme as a percentage of the cost of the programme, is reported in Table 6 following equation (12).

Table 4 presents values of social welfare for four alternative scenarios: first is the current situation when Dibao is operational; second, if Dibao did not exist; third if Dibao had perfect targeting; and fourth when Dibao had no targeting, and everyone received the same transfers. In the calculation of social welfare under the first, third and fourth scenarios, the total transfers going to beneficiaries are kept the same at Yuan 19.8 billion. We explain the calculation of social welfare as follows:

Per capita disposable income is Yuan 9,850 per year, which when multiplied by the rural population of 620.22 million, results in the total disposable income available to the rural population equivalent to 6,109 billion. This figure includes the total transfers of 19.8 billion to beneficiaries of the programme. The existence of poverty incurs a loss of social welfare, the magnitude of which depends on the poverty measure used. The loss of social welfare for the poverty gap ratio, as calculated from (10), is equal to 82 billion, which when subtracted from the total disposable income gives social welfare equal to 6,027 billion, which is the social welfare of the rural population when Dibao is operational.

Let us now consider the counterfactual if Dibao had not existed, in which case the total disposable income will be reduced by the total programme transfers of 19.8 billion. If the 
programme is not operational, the incidence of poverty will also be higher, which will lead to higher loss of social welfare due to poverty. We calculated this loss to equal Yuan 86 billion, which when subtracted from the disposable income available to the population without the programme equates to social welfare totaling Yuan 6,003 billion. The calculation of social welfare under the perfect targeting and universal basic income follows the same procedure.

Table 4: Social Welfare under various scenarios (Yuan billion per year)

\begin{tabular}{|l|l|l|}
\hline Poverty & Per capita real & Per capita real \\
\hline Measure & disposable income & consumption \\
\hline & Dibao operational & \\
\hline Poverty gap ratio \% & 6027 & 4761 \\
\hline $\begin{array}{l}\text { The severity of } \\
\text { poverty \% }\end{array}$ & 5912 & 4754 \\
\hline & With no Dibao & \\
\hline Poverty gap ratio \% & 6003 & 4737 \\
\hline $\begin{array}{l}\text { The severity of } \\
\text { poverty \% }\end{array}$ & 5887 & 4727 \\
\hline $\begin{array}{l}\text { The severity of } \\
\text { poverty \% }\end{array}$ & 5908 & 4749 \\
\hline poverty \% & Perfect Targeting & \\
\hline Poverty gap ratio \% & 6043 & 4777 \\
\hline & 5955 & 470 \\
\hline
\end{tabular}

Each scenario generates a different value of social welfare. A scenario which creates the highest level of social welfare will contribute most to the poverty reduction with a given programme cost. The difference in social welfare with the programme and without the programme measures the contribution of that programme. For instance, social welfare with Dibao equal to Yuan 6,027 
billion while social welfare without a programme is Yuan 6,003, which implies that Dibao contributes social welfare equal to Yuan 24 billion per year.

Table 5 presents the contributions to social welfare for three alternative scenarios. The contributions are the results of the values of social welfare under each of the three scenarios minus the values under no Dibao. As expected, perfect targeting generates much larger social welfare than the other two. Although Dibao creates more social welfare than the universal basic income, the difference between them is small and may not be significant. A critical policy question is: should a universal basic income replace the current Dibao? The answer depends on the costs of running the two programmes.

Table 5: Contribution to social welfare for three alternative scenarios

\begin{tabular}{|l|l|l|}
\hline Poverty & Per capita real & Per capita real \\
\hline Measure & disposable income & consumption \\
\hline Poverty gap ratio \% & 24 & 24 \\
\hline $\begin{array}{l}\text { The severity of } \\
\text { poverty \% }\end{array}$ & 25 & 27 \\
\hline $\begin{array}{l}\text { Phe severity of } \\
\text { poverty \% }\end{array}$ & 68 & 40 \\
\hline & Perfect targeting & 42 \\
\hline $\begin{array}{l}\text { Poverty gap ratio \% } \\
\text { poverty \% }\end{array}$ & No targeting universal & \\
\hline Poverty gap ratio \% & 21 & 21 \\
\hline & 21 & \\
\hline
\end{tabular}

The SRR takes into account the operational costs of running a programme. The universal basic income does not explicitly target the poor. It makes equal transfers to all individuals in the population, so the administrative cost as a share of total transfers will almost be negligible. It does not require identifying the poor. It is reasonable to assume that the administrative cost of sending transfers to all citizens will not be more than $5 \%$ of the total transfers. The total transfers 
going to beneficiaries are 19.8 billion Yuan, and with 5\% administrative cost, total programme cost will be 20.8 billion Yuan. So the social rate of return will be $0.01 \%$ (21/20.8-1), which is slight. Thus, universal basic income generates an insignificant social rate of return.

As pointed out earlier, the total transfers going to Dibao from all levels of government was about 87 billion Yuan in 2013 as reported by Official Statistics for China's Rural Dibao programme. Assuming that 87 billion Yuan is the correct cost of running Dibao, which is justified because it is an official figure, then social rates of returns for Dibao are profoundly negative; around -70\% as shown in Table 6. Any programme with such high negative rates of return cannot be sustained. There is an urgent need for reforming the targeting methodology used for Dibao. If the local governments followed a universal basic scheme, which does not require targeting the poor, rural Dibao could have avoided such high negative rates of return.

We could not present the estimates of SRR under the scenario of perfect targeting because we are unable to estimate the administrative cost of perfect targeting. We are even sceptical whether it is at all possible to achieve perfect targeting as even developed countries do not have perfect targeting in their social assistance programmes. Undoubtedly more efficient targeting has evolved in developed countries, but there will still be some degree of leakage. To aspire for perfect targeting is an unachievable goal, which we do not recommend for Dibao but targeting can be improved substantially.

Table 6: Social Rates of Return for Dibao

\begin{tabular}{|l|l|l|}
\hline Poverty & Per capita real & Per capita real \\
\hline \multicolumn{2}{|c|}{ disposable income } \\
\hline Measure & \multicolumn{2}{c|}{ consumption } \\
\hline Poverty gap ratio \% & -72.99 & -71.89 \\
\hline Severity of poverty \% & -70.81 & -69.87 \\
\hline
\end{tabular}

\section{Concluding remarks and recommendations}

This paper developed some new methods for evaluating the targeting efficiency and the social rate of return for social programmes and applied them for rural Dibao using CHIP2013 data. We found that there have been severe problems with targeting efficiency, yielding significant negative social rate of return. Precisely: 1) The selection of an individual in the Dibao programme is not determined by the poverty status of the individual, measured by income. 2) Dibao selection excludes almost $87 \%$ of the poor while including about $82 \%$ of the non-poor. 3 ) There is considerable inequity in the payment of programme benefits to the poor and non-poor, where the poor beneficiaries receive much less than non-poor beneficiaries. 4) The percentage of 
total resources leaked out to the non-poor is even higher than the leakage of beneficiaries. 5) Dibao yields high negative social rate of return for both the poverty gap ratio and the severity of poverty.

The evaluation of Dibao was performed using the two alternative household welfare measures: (i) real per capita disposable income and (ii) real per capita household consumption. Both welfare measures tell the same story; that Dibao does not achieve its primary objective of reducing poverty at minimum cost. The cost of running Dibao is extraordinarily high with an insignificant impact on poverty reduction. If China aims to eliminate poverty by 2020 , then Dibao needs to be urgently reformed by improving its targeting efficiency and reducing its administrative cost.

The central message emerging from this paper is that the rural Dibao is in need of an efficient mechanism and methodology for identifying the poor and determining the amount of subsidy needed. The management of Dibao is highly decentralized, and local governments do not follow precise targeting system. This paper does not argue that Dibao should be completely centralized; the programme should be run by local authorities who are more familiar with local conditions. However, local authorities may not possess the technical capacity to implement complicated targeting methodology. This paper recommends that there should be a central authority, which develops a consistent targeting framework which could be used by local governments. The implementation of such a framework should be carried out by local governments. The central authority can provide training on targeting methods to the local administration officials and communities involves the operation of Dibao. It can also develop monitoring systems to ensure that the programme is efficiently running at the local level.

Given the limitations of accurately obtaining people's income or consumption, many developing countries use the proxy means test as a targeting framework. The basic idea of a proxy means test is to identify beneficiaries by easily identifiable variables that accurately predict a household to be in poverty. There is a now emerging literature on targeting such as Brown et al. (2016), in which the performance of various proxy-means testing methods is assessed. They argue that even with a budget sufficient to eliminate poverty with full information, none of these targeting methods reduce the poverty rate below three-quarters of its initial value, and the current methods are notably deficient in reaching the poorest.

In response to those problems with social programmes, we are developing a new proxy means test for poverty targeting. A nationally representative household survey makes it possible to design such a proxy means test. The first step in designing a proxy means testing is to identify a set of variables highly correlated with the poverty status of households. These selected variables must be accessible to measure but at the same time should be able to predict with reasonable accuracy the poverty status of households. To accomplish this objective, we develop a formula to 
calculate a correlation coefficient between any proxy variable with the poverty status of households. This correlation coefficient helps in identifying the proxy variables.

The proxy means test we are experimenting with and developing in China consists of a decision rule that determines which household should or should not be included in the programme. One can arrive at such a decision rule by a set easily identifiable by proxy variables at the household level. The local authorities can collect information on proxy variables from households using a small questionnaire.

Such a system will be an objective way of selecting beneficiaries of the programme. We believe that such a system will significantly improve targeting and reduce the cost of running the programme. That should help China to achieve its goal of eradicating extreme poverty by 2020 . 


\section{Appendix}

Because part of Dibao funding is from local governments and because the Dibao line is determined by local governments, an affluent region would have a higher Dibao line and a poor region tends to have lower Dibao lines.

Table A shows the average per capita income of all households and Dibao households, and the Dibao line in 2013 across different provinces in China. It can be seen that there are large differences in Dibao lines between different provinces. The provinces with higher Dibao lines are those in the more developed eastern coastal areas such as Beijing, Jiangsu, and Guangdong provinces. The less developed Central and Western regions such as Henan, Gansu and Yunnan, have lower Dibao lines. The Dibao line in Beijing is more than three times higher than those provinces at the bottom. ${ }^{8}$

Judging from the ratio of the Dibao standard and household per capita income, most Dibao allowances in the surveyed provinces are less than one quarter of the per capita income of rural households.

Gansu, Liaoning, and Jiangsu provinces have a high rate of Dibao coverage, while Henan and Guangdong provinces have a lower rate of coverage. For Henan Province, the Dibao line is very low (1,772 yuan/person/year), which is far lower than the per capita income of both Dibao households and whole population. Therefore, the lower rate of Dibao coverage in Henan Province is mainly due to a lower Dibao line as a result of shortage of funds. Guangdong's Dibao standard is high compared with other provinces, but are not high compared to their own income and income levels. Their ratio of Dibao allowances to per capita income is lower than that of Jiangsu province, which is at similar level of development.

\footnotetext{
${ }^{8}$ Considering that the Dibao programme is treated as an insurance program (Doudi 睍底) in rural areas, if the Dibao line is always lower than the national poverty line, the program will not effectively lift the poor out of poverty, even if it more effectively targeted.
} 
Table A. Different Income Levels and Dibao Lines Cross Provinces (Yuan/person/year)

\begin{tabular}{|l|r|r|r|}
\hline Provinces & $\begin{array}{r}\text { Average per } \\
\text { capita income of } \\
\text { whole sample }\end{array}$ & $\begin{array}{r}\text { Average per } \\
\text { capita income of } \\
\text { Dibao households }\end{array}$ & Dibao line \\
\hline Beijing & 19,401 & 11,121 & 6,019 \\
\hline Shanxi & 9,718 & 5,449 & 2,076 \\
\hline Liaoning & 12,697 & 7,707 & 2,623 \\
\hline Jiangsu & 16,819 & 7,276 & 4,993 \\
\hline Anhui & 12,141 & 9,724 & 2,026 \\
\hline Shandong & 15,194 & 7,065 & 2,710 \\
\hline Henan & 11,524 & 8,965 & 1,772 \\
\hline Hubei & 13,013 & 9,396 & 2,004 \\
\hline Hunan & 11,821 & 6,370 & 1,862 \\
\hline Guangdong & 15,669 & 6,340 & 3,676 \\
\hline Chongqing & 10,542 & 4,333 & 2,394 \\
\hline Sichuan & 10,797 & 7,973 & 2,217 \\
\hline Yunnan & 11,475 & 6,140 & 1,924 \\
\hline Gansu & 7,955 & 6,041 & 1,839 \\
\hline National & 12763 & 7242 & 2608 \\
\hline
\end{tabular}

Notes: average income excludes Dibao subsidy. Household income is from CHIP2013, Dibao line is from MOCA (2014) 


\section{References}

Brown, Caitlin., Martin Ravallion, and Dominique van de Walle 2016, "A Poor Means Test? Econometric Targeting in Africa”, NBER Working Paper No. 22919.

Chen, Shaohua., Ravallion, Martin., \& Wang, Youjuan. (2006). "Does the Dibao Program Guarantee a Minimum Income in China's Cities?" in Jiwei Lou and Shuilin Wang (eds)

Public Finance in China: Reform and Growth for a Harmonious Society, Washington DC: World Bank.

Coady David., Margaret Grosh John Hoddinott, 2004, Targeting of Transfers in Developing Countries: Review of Lessons and Experience, Washington: the World Bank.

Gao, Qin., Garfinkel, Irwin., \& Zhai, Fuhua. 2009, “Anti-Poverty Effectiveness of the Minimum Living Standard Assistance Program in Urban China". Review of Income and Wealth, 55 (special issue 1): 630-655.

Gao, Qin., and Fuhua Zhai, 2012, “Anti-Poverty Family Policies in China: A Critical Evaluation", Asian Social Work and Policy Review, 6: 122-135

Golan, Jennifer., Terry Sicular, and Nithin Umapathi, 2017, "Unconditional Cash Transfers in China: Who Benefits from the Rural Minimum Living Standard Guarantee (Dibao) Program?” World Development, 93(5): 316-336.

Foster, James., Greer, Joel., Thorbecke, Erik., 1984, “A Class of Decomposable Poverty Measures". Econometrica, 52(3), 761-776

Grosh, Margaret E., and Judy L. Baker, 1995, "Proxy Means Tests for Targeting Social Programs: Simulations and Speculation", The Living Standards Measurement Study.

Gustafsson, Bjorn, Shi Li, Sicular 2008. Income Inequality and Public Policy in China Inequality and Public Policy in China, New York, NY: Cambridge University Press

Gustafsson, Bjorn, Shi Li, and Hiroshi Sato, 2014, "Data for Studying Earnings, the Distribution of Household Income and Poverty in China", China Economic Review, 30: 419-431.

Han, Huawei., and Qin Gao. 2017. "Protective effectiveness of Dibao in rural China: Empirical evidence from China Family Panel Studies". Journal of Public Management (in Chinese), 14(2): 81-96.

Haushofer, Johannes., and Jeremy Shapiro, 2016. "The Short-term Impact of Unconditional Cash Transfers to the Poor: Experimental Evidence from Kenya". Quarterly Journal of Economics, 131(4): 1973-2042.

Li, Shi., 2014, "Poverty Reduction and Effects of Pro-poor Policies in Rural China", China and World Economy, 22(2): 22-41.

Li, Shi., and Terry Sicular, 2014, "The Distribution of Household Income in China: Inequality, Poverty and Policies", The China Quarterly, 217: 1-41

Li Shi, Hiroshi Sato and Terry Sicular 2013, Rising inequality in China: Challenges to a Harmonious Society. New York, NY: Cambridge University Press

Kakwani, Nanak., and Hyun Son, 2005, "On Assessing Pro-poorness of Government Programmes: International Comparisons". Chapter 13. in Kakwani and Silber (eds.) The Many Dimensions of Poverty. London. Palgrave Macmillan.

Kakwani, Nanak., and Hyun Son, 2008, "Poverty Equivalent Growth Rate", Review of Income and Wealth, 54(4): 643-65

Kakwani, Nanak., and Hyun Son, 2016, Social Welfare functions and Development: Measurement and Policy Applications. London. Palgrave Macmillan

Kakwani, Nanak., Shi Li, Xiaobing Wang, and Shanshan Wu, 2018 "Social Tensions in Growing China", The Manchester School, forthcoming 
Ministry of Civil Affairs (MOCA), 2014. Shehui Fuwu Fazhan Tongji Gongbao (Statistical Communique on the Development of Civil Affairs).

http://www.mca.gov.cn/article/sj/tjgb/.

Ravallion, Martin., 2009, 'How relevant is targeting to the success of an antipoverty program?', The World Bank Research Observer, 24(2): 205-231.

Wang, M. (2007). "Emerging urban poverty and effects of the Dibao program on alleviating poverty in China". China and the World Economy, 15(2), 74-88.

Zhang, Li., Xinye Zheng, Fanghua Li and Yihua Yu, 2016, "Designing the Minimum Living Standard Assistance: Looking Back, Looking Around, and Looking Ahead?”, Working Paper. 


\section{Highlights}

- The selection of an individual in the rural Dibao program not determined by the poverty status of the individual measured by income or consumption.

- Rural Dibao program excluded almost $87 \%$ of the poor while included about $82 \%$ of the non-poor in 2013.

- The poor beneficiaries get much less than those non-poor beneficiaries.

- The percentage of total resources leaked out to the non-poor is even higher than the leakage of beneficiaries.

- Rural Dibao program yielded high negative social rate of return for both the poverty gap ratio and the severity of poverty. 